\title{
A tríade plano de texto, argumentação e autoria na redação do Enem
}

\section{Cristiane Dall' Cortivo Lebler}

Docente da Universidade Federal de Santa Catarina (UFSC), Brasil orcid.org/0000-0003-3389-1850

\section{Luiza Guimarães Lanes}

Mestranda em Letras Vernáculas pela Universidade Federal do Rio de Janeiro (UFRJ), Brasil orcid.org/0000-0002-7008-9122

Argumentação e autoria são qualidades desejáveis a textos de todos os gêneros. Um dos fatores que favorecem essas características é o planejamento macroestrutural, também conhecido como plano de texto (ADAM, 2005; MARQUESI et al, 2019; MARQUESI; ELIAS; CABRAL, 2017). Tendo como objeto a análise de uma redação do Enem 2019, este artigo objetiva discutir a relação entre plano de texto, argumentação e autoria. Para isso, serão mobilizados conceitos da Linguística Textual e os critérios propostos pelo Inep para a correção de textos dissertativo-argumentativos (BRASIL, 2019; 2020). Quanto à metodologia, trata-se de uma pesquisa bibliográfica de cunho qualitativo. Os resultados mostraram que o exemplar de redação nota 1000 analisado apresenta a defesa de um ponto de vista sustentado por uma argumentação autoral e consistente, sob a qual se depreende um plano de texto, comprovando, desse modo, que plano de texto, argumentação e autoria constituem uma tríade interdependente.

Palavras-chave: Plano de texto. Autoria. Argumentação. Texto dissertativo-argumentativo.

\section{La tríada plan del texto, argumentación y autoría en la escritura de Enem}

La argumentación y la autoría son cualidades deseables para textos de todos los géneros. Uno de los factores que favorecen estas características es la planificación macroestructural, también conocida como plan de texto (ADAM, 2005; MARQUESI et al, 2019; MARQUESI; ELIAS; CABRAL, 2017). Teniendo como objeto el análisis de un ensayo Enem 2019, este artículo tiene como objetivo discutir la relación entre el plan de texto, la argumentación y la autoría. Para ello, se movilizarán conceptos de Lingüística Textual y los criterios propuestos por el Inep para la corrección de textos disertativosargumentativos (BRASIL, 2019; 2020). En cuanto a la metodología, se trata de una investigación bibliográfica de carácter cualitativo. Los resultados mostraron que la nota de redacción 1000 analizada presenta la defensa de un punto de vista sustentado en una argumentación autoral y consistente, bajo la cual se induce un plan de texto, demostrando así que el plan de texto, la argumentación y la autoría constituyen una tríada interdependiente.

Palabras clave: Plan de texto. Autoría. Argumentación. Texto disertativo-argumentativo.

\section{The triad text plan, argumentation, and authorship in Enem essays}

Argumentation and authorship are desirable qualities for texts of all genres. One of the factors favoring these characteristics is macrostructural planning, also known as text plane (ADAM, 2005; MARQUESI et al, 2019; MARQUESI; ELIAS; CABRAL, 2017). The present article, which has as its object the analysis of an essay from Enem 2019, aims to discuss the relationship between text plan, argumentation, and authorship. To do so, we mobilize concepts from Text Linguistics and the criteria proposed by Inep for the evaluation of argumentative essays (BRASIL, 2019; 2020). As for the methodology, it is bibliographic research of qualitative nature. The results showed that the model essay analyzed presents the defense of a point of view supported by an authorial and consistent argumentation, from which a text plan is inferred, thus proving that text plan, argumentation and authorship constitute an interdependent triad.

Keywords: Text plan. Authorship. Argumentation. Argumentative essays. 


\section{Introdução}

Quando se fala em texto dissertativo-argumentativo, muito embora se use uma terminologia que remeta às tipologias textuais (ADAM, 2005; MARCUSCHI, 2010), naturalmente se faz equivalência desse tipo de texto a um gênero específico - a redação de vestibular ou Enem. Para além de toda a discussão que a abordagem desse tema já protagonizou, sob diferentes olhares teóricos, e de todas as problemáticas envolvidas no seu tratamento escolar (e aqui se faz menção especialmente ao fato de se tratar de um gênero que circula exclusivamente nessa esfera, o que the confere um caráter altamente escolarizado), as avaliações em larga escala, particularmente o Enem e os vestibulares em sua maioria, adotam-no como o padrão de produção textual com a finalidade de avaliar a capacidade de expressão escrita dos estudantes.

Assim, ao se considerar o fato de esse gênero circular amplamente no universo escolar, especialmente nas aulas de língua portuguesa e redação, é fundamental que pesquisadores e professores permaneçam refletindo a respeito de como, por meio dele, é possível pensar o desenvolvimento e o aprimoramento da competência discursiva escrita de estudantes e de como transformá-la em uma ferramenta, por meio da qual os alunos reflitam sobre os problemas sociais com os quais se deparam cotidianamente.

Além disso, discutir como a avaliação desses textos pode potencializar essa habilidade também continua sendo um tema presente na ordem do dia, especialmente quando tomada em uma dimensão formativa, já que os conhecimentos que os estudantes precisam acionar para produzir textos com qualidade são de diferentes naturezas, muitos dos quais, inclusive, são gerais e comuns à escrita de inúmeros outros gêneros.

A escrita é um processo complexo. Para que ela aconteça, vários conhecimentos, de diferentes ordens, precisam ser mobilizados: conhecimentos acerca da norma padrão escrita da língua, da estrutura composicional do gênero a ser produzido, da estrutura tipológica e das estratégias de organização e de planejamento textual, conhecimentos de ordem temática e outros ainda que envolvem a situação enunciativa que reveste essa produção, como as esferas de circulação desse gênero e as suas intencionalidades.

Sendo as problemáticas que perpassam a produção e a avaliação de textos dissertativo-argumentativos vastas e amplas, e conscientes da limitação e do propósito deste texto, tem-se como objetivo, neste artigo, discutir um aspecto singular e fulcral a qualquer produção escrita: a relação entre plano de texto, argumentação e autoria. Esses aspectos, além de fundamentais para a escrita, compõem a matriz de referência do Exame Nacional do Ensino Médio para avaliação de textos dissertativo- 
argumentativos, e a sua observância pode ser considerada como um preditor de sucesso nesse tipo de produção. Para fundamentar este trabalho, parte-se de diferentes aportes teóricos, dentre os quais os princípios da Linguística Textual e as diretrizes de avaliação propostas pelo Instituto Nacional de Estudos e Pesquisas Educacionais Anísio Teixeira (Inep) para a atribuição de nota às redações do Enem ${ }^{1}$.

Este texto terá, pois, a seguinte estrutura: seu início tratará da relação entre plano de texto, argumentação e autoria, especialmente a partir dos pressupostos da Linguística de Texto, com ênfase no planejamento e na escrita textual; em seguida, será abordada a avaliação desses aspectos a partir dos critérios de avaliação da redação Enem (BRASIL, 2019)2. Como forma de ilustrar de maneira transversal esses conceitos, serão apresentados comentários sobre uma redação publicada no Caderno do Participante (BRASIL, 2020), que recebeu nota 1000 no Enem de 2019.

\section{Plano de texto, argumentação e autoria}

É fato que o atravessamento das tecnologias na mediação de nossas interações tem demandado novas habilidades de leitura e de produção de textos: memes, podcasts, postagens em redes sociais (Instagram, Facebook, Twitter), uso de ambientes virtuais de ensino-aprendizagem (AVEAs) etc. exigem estratégias de interação com os textos que vão além da leitura linear e da linguagem verbal escrita. Assim, pode-se considerar o universo da produção textual extremamente vasto e não unicamente restrito ao uso do signo linguístico agenciado em discursos. A Base Nacional Comum Curricular (BRASIL, 2018), ao propor, por exemplo, a análise linguística/semiótica como um dos eixos a partir dos quais se organizam as habilidades e os objetos de conhecimento, apresenta um reconhecimento, inclusive em termos de políticas públicas, da necessidade de que se abordem as linguagens no ensino de língua materna (SANTOS; LEBLER, 2021).

Essa vasta gama de sistemas semióticos imbricados na produção textual escrita é indicativo de que essa atividade não pode ser pensada nas dimensões de ensinoaprendizagem e avaliação apenas quanto à adequação à norma-padrão da língua. Inclusive, as próprias questões objetivas de Linguagens do Enem vão de encontro a essa supervalorização da norma-padrão, enfatizando a pluralidade da Língua

\footnotetext{
1 Outras abordagens teóricas poderiam também ser empregadas na análise da argumentação, a exemplo da Retórica aristotélica e da Nova Retórica, da Teoria dos Blocos Semânticos, de Carel e Ducrot, e da Teoria Semiolinguística, de Patrick Charaudeau. A escolha do recorte teórico apresentado se deve pelo seu diálogo mais próximo com a Matriz de Referência para Redação Enem, ao abordar os conceitos de plano de texto, coerência, argumentação e sequências textuais que, por sua vez, aparecem de forma explíita na competência III da referida matriz.

${ }^{2}$ Ressalta-se que o material que embasará a abordagem do tema, apesar de receber a nota de conteúdo sigiloso, está disponível para download no próprio site do Inep, em: https://download.inep.gov.br/educacao_basica/enem/downloads/2020/Competencia_3.pdf . Acesso em: 20 dez. 2021.
} 
Portuguesa por meio de enunciados que abordam, por exemplo, a variação linguística e a oralidade.

Contudo, quando a reflexão se volta aos textos redigidos em linguagem verbal escrita, por exemplo, trabalhos como o de Barbisan (2005) e de Possenti (2002) já mostraram, há quase duas décadas, que a qualidade de um texto não pode ser medida meramente pela presença/ausência de erros de gramática ou de pontuação. Para Barbisan (2005), a falta mais sensível a um texto dissertativo-argumentativo diz respeito à qualidade da argumentação, especialmente quando se observam as relações semânticas presentes em um texto; já Possenti (2002) aponta a autoria como qualificadora da produção escrita. Além disso, autores como Adam (2005), Cabral (2013), Marquesi, Elias e Cabral (2017), Marquesi et al (2019), Oliveira e Queiroz (2020) já demonstraram que o plano de texto deve ser tido como fator crucial para a qualidade textual.

Assim, circunscrita à produção textual em linguagem verbal, esta seção buscará dialogar com estudos já realizados que abordem os conceitos de plano de texto, argumentação e autoria, inter-relacionados ou não, com vistas a oferecer os fundamentos a partir dos quais essas dimensões possam ser avaliadas na produção de textos dissertativo-argumentativos, sobretudo, na redação modelo Enem.

Veja-se a noção de autoria. Para Possenti (2002), a diferença entre bons textos e textos sem personalidade está na presença/ausência de autoria. Para o pesquisador, essa característica repousa sobretudo no "como" dizer: importa não apenas aquilo que se diz, mas também o modo como o locutor de um texto agencia suas ideias e as transforma em matéria verbal. Esse modo de transformar a língua em discurso, prossegue Possenti, conduz à ideia de singularidade do dizer, que só pode ser avaliada se observada em sua dimensão discursiva.

Jean-Michel Adam (2005), ao introduzir a abordagem que denomina análise textual dos discursos, expõe também as definições de texto, discurso e de gêneros discursivos. Para o autor (2005, p. 28-29), os textos são objetos concretos, que se apresentam como um enunciado completo, mas não isolado de outros textos, fruto de um ato de enunciação particular. Assim, a análise textual dos discursos deve abordar tanto a dimensão da articulação textual quanto a dimensão discursiva de seu objeto, qual seja, o texto.

A autoria, entendida também como o estilo individual (POSSENTI, 2005), pode encontrar maior ou menor possibilidade de emergência, tendo em vista as restrições impostas por determinados gêneros: há gêneros em que a liberdade criativa e estilística é maior, como, por exemplo, em contos ou em crônicas e na maior parte dos gêneros literários; já há outros gêneros em que a liberdade de estilo - e, portanto, da emergência da autoria - é mais limitada, e o texto dissertativo-argumentativo é um desses exemplos. 
Entretanto, limitação não significa ausência, e é certo que existem estratégias linguístico-discursivas capazes de alcançar a autoria nesse tipo textual.

Ainda de acordo com Adam (2005), "um texto está constituído de partes sucessivas, espécies de subtextos no interior de um texto. Para reconhecer um texto como um todo, é preciso perceber um plano de texto, com suas partes e/ou um agenciamento de sequências"3 (2005, p. 175, tradução nossa). Tem-se, assim, que o plano de texto, parafraseando Adam (2005), é o elemento que lhe confere unidade, é o elemento a partir do qual se pode perceber um texto como um todo que expressa uma unidade temática e ilocucionária (2005, p. 175), apesar da possibilidade de decompô-lo em subunidades. O plano de texto, pois, pode ser aproximado à disposição, uma das partes do sistema retórico descrito por Aristóteles (REBOUL, 2004), momento em que o orador planeja seu discurso aplicando-Ihe a estratégia mais conveniente para alcançar a adesão de seu auditório, ou seja, quando o orador recolhe e organiza os argumentos que sustentarão a tese que será defendida.

O plano de texto assim concebido é algo que antecede a produção textual, pela definição da tese que será defendida e da forma linguístico-discursiva que assumirá, pela escolha e ordenação dos argumentos, pela seleção das vozes que serão mobilizadas como provas discursivas, além da definição de uma intenção, que revestirá o texto de uma maneira geral. Dessa forma, entende-se, com Adam (2005), que o plano de texto subjaz à macroestrutura textual e, apesar de, na produção, anteceder a escrita propriamente dita, pode ser resgatado durante a leitura: ele "reflete a maneira como as informações estão organizadas no texto, indicando também a organização das sequências textuais, sempre de acordo com as intenções de quem escreve" (MARQUESI; ELIAS; CABRAL, 2017, p. 14).

Em uma correlação estreita com a definição de texto proposta por Adam (2005), em que este é concebido como um todo composto de subunidades, o plano de texto deixa entrever tanto essas subunidades que o compõem quanto permite justificar a ordem em que são apresentadas. O autor explicita que a estrutura composicional de um texto comporta diferentes sequências textuais: assim, em um texto dissertativoargumentativo, encontra-se como predominante a sequência argumentativa; contudo, outras também podem ser encontradas, como as descritivas e as explicativas. A escolha pela sequenciação e pelo encadeamento dessas estruturas tem relação estreita com a argumentação e com a autoria. Veja-se um exemplo de redação retirado da Cartilha do Participante (BRASIL, 2020, p. 33); trata-se do parágrafo introdutório do texto:

\footnotetext{
3 "Un texte est constitué de morceaux successifs, sortes de soustextes à l'interieure du texte. Pour reconnaître un texte comme tout, il faut percevoir un plan de texte, avec ses parties et/ou agencement de séquences" (ADAM, 2005, p. 175).
} 
Para o filósofo escocês David Hume, a principal característica que difere o ser humano dos outros animais é o poder de seu pensamento, habilidade que o permite ver aquilo que nunca foi visto e ouvir aquilo que nunca foi ouvido. Sob essa ótica, vê-se que o cinema representa a capacidade de transpor para a tela as ideias e os pensamentos presentes no intelecto das pessoas, de modo a possibilitar a criação de novos universos e, justamente por esse potencial cognitivo, ele é muito relevante. É prudente apontar, diante disso, que a arte cinematográfica deve ser democratizada, em especial no Brasil - país rico em expressões culturais que podem dialogar com esse modelo artístico -, por razões que dizem respeito tanto à sociedade quanto às leis.

Conforme já apontaram Cabral (2013) e Marquesi, Elias e Cabral (2017), é possível identificar a existência de um plano de texto quando se realiza a leitura desse trecho. Assim, a análise do parágrafo acima transcrito permite que sejam identificadas as estratégias mobilizadas pelo seu autor para a construção da argumentação e o modo como o agenciamento das formas linguísticas ganha particularidade, elemento fundamental para a presença da autoria. A leitura que se propõe aqui não se restringirá à identificação e à descrição das sequências argumentativas, mas evidenciará também como outros elementos, denominados estratégias, são agenciados para a construção da argumentação.

A primeira estratégia de que o autor faz uso é a argumentação por autoridade (PLATÃO; FIORIN, 2005). Esse tipo de argumento sustenta-se na credibilidade dada à fonte cuja voz é inserida no texto. Assim, esse recurso atende não só o que Possenti (2002) aponta como um dos critérios para a definição de autoria, que é dar voz aos outros, mas também dá consistência ao ponto de vista que se busca defender: não se trata simplesmente da opinião do autor do texto, mas de uma afirmação cujos contornos têm ares de ciência.

Além disso, o locutor desse texto garante sua argumentação não apenas por evocar a quem essa voz precisa ser assimilada, mas também por descrever esse "quem": um filósofo escocês. A opção pela descrição deixa transparecer a imagem do leitor de seu texto, que pode desconhecer a figura de David Hume, fato que arruinaria sua estratégia argumentativa. Assim, ao caracterizá-lo como filósofo, o locutor tanto atribui um grau de importância à fonte da voz que insere no texto quanto garante que essa importância seja reconhecida - afinal, se são analisados os sentidos atribuídos a "filósofo", certamente se encontrará algo como "fonte da sabedoria e da verdade". Temse, aqui, portanto, uma estratégia de caráter retórico-discursivo, que faz parte do planejamento textual do seu locutor, e a mobilização de uma sequência textual descritiva, que, mesmo implicando essa carga de descrição, reforçou a argumentação do candidato.

Uma segunda estratégia usada nesse texto está em lançar mão da definição de "poder de pensamento", também considerada uma sequência textual descritiva, 
caracterizada por "determinar a extensão ou os limites de, enunciar os atributos essenciais e específicos do ente descrito, para que ele não seja confundido com outro" (MARQUESI; ELIAS; CABRAL, 2017, p. 18): nesse caso, a estratégia é linguística e servirá de base para a continuidade da argumentação, já que é a especificidade do poder de pensamento, definido como uma habilidade criativa exclusiva do ser humano, que torna possível a idealização de mundos por meio do cinema. Além disso, o cinema é, ao mesmo tempo, produto e evidência dessa capacidade humana: é porque o humano é capaz de criar que o cinema existe, e é porque o cinema existe que essa capacidade humana se torna palpável.

É no enunciado seguinte que a sequência argumentativa aparece, sob a forma de justificação. Marquesi, Elias e Cabral (2017, p. 24) esquematizam a sequência argumentativa como constituída de dados ou fatos, sustentação ou princípios de base e conclusão e serve para demonstrar ou justificar uma tese ou para refutar argumentos contrários ou outras teses. No parágrafo em análise, o movimento realizado é o de demonstração de uma tese - a necessidade de democratizar o cinema pela sua relevância, decorrente da possibilidade de criação de novos universos, ou seja, o cinema é relevante porque possibilita a criação de novos mundos, logo precisa ser democratizado.

Na continuidade do parágrafo, é encadeada outra sequência descritiva, desta vez a individuação, caracterizada por Marquesi, Elias e Cabral (2017, p. 18) como aquela "que se destina a especificar, distinguir, ou seja, particularizar, tornar individual. Essa última categoria indica o que dá ao ente descrito uma existência singular, determinada no tempo e no espaço". Trata-se da individuação de "Brasil", caracterizado pela sua riqueza cultural, subsídio para o desenvolvimento cinematográfico no país. Por fim, são apontados os argumentos que serão desenvolvidos nos parágrafos seguintes e que darão sustentação à tese: as razões sociais e legais que justificam a necessidade de democratização do cinema. A título de sistematização, encontra-se um esquema que resume as sequências textuais supracitadas:

\section{Plano de texto - parágrafo introdutório}

a) sequências textuais mobilizadas

Sequência descritiva: David Hume, filósofo escocês

Sequência descritiva: definição de poder de pensamento

Sequência argumentativa: apresentação da tese a ser defendida

O cinema é relevante, logo precisa ser democratizado

Sequência descritiva: individuação de Brasil 
Assim, se procurou demonstrar, pela análise desse parágrafo, a. que ele é constituído de uma sequência de estruturas textuais, as quais revelam b. o plano de texto, ou seja, o modo como o autor escolheu organizar o seu projeto de dizer. Ressaltase que esse modo de dizer, esse plano de texto, é responsável pelo encadeamento das ideias e conduz, naturalmente, o leitor pelo desenvolvimento da sua argumentação: apresenta claramente um ponto de vista e evidencia os argumentos que o sustentarão; encadeia as ideias de forma a manter a temática do texto e, ao mesmo tempo, progredila; e desenvolve as ideias por meio de explicitações, exemplificações, etc.

Afinal, então, qual a relação entre plano de texto, argumentação e autoria? Em que medida essas três dimensões estão imbricadas e podem ser resgatadas no texto? A existência de um plano de texto, que se evidencia na leitura, diz respeito também ao estabelecimento de estratégias argumentativas, seja pela escolha e pelo agenciamento lexical, seja pela forma linguística que se dá a esses argumentos, ou ainda pela própria ordem em que esses argumentos são apresentados e pela força atribuída a eles quando colocados em relação por determinados operadores argumentativos (DUCROT, 1987). Para Marquesi, Elias e Cabral (2017), o planejamento se dá em duas etapas: primeiramente, são resgatados os conhecimentos e as ideias que serão mobilizados para a defesa de um ponto de vista, tanto aqueles temáticos quanto outros de natureza linguístico-discursiva, referentes à estrutura dos gêneros e às suas intencionalidades, às tipologias textuais etc; após, esses conhecimentos e ideias precisam ser organizados.

Nessa ótica, sendo o plano de texto singular a cada produção, não se pode confundi-lo com uma receita passível de aplicação a todos os contextos, mas cabe, sim, tratá-lo como uma ferramenta que se mostra efetiva para o planejamento da estrutura global do texto. Seu uso culminará na clareza do ponto de vista defendido e dos argumentos usados na sua sustentação, no encadeamento desses argumentos, de forma a garantir tanto a reiteração temática quanto a sua progressão, no uso de estratégias diversificadas para a demonstração da argumentação, tais como a exemplificação, a definição, a explicitação de outras vozes etc, alcançando, finalmente, de maneira empírica, o que Adam (2005) define como texto - um enunciado completo e o que Possenti (2002) descreve como autoria - a forma singular com que um locutor diz o que diz.

Em suma, o projeto de texto fomenta maior grau de argumentação e autoria, uma vez que articula, antecipadamente, os caminhos a serem trilhados com vistas a defender um ponto de vista e a imprimir uma autoria. Isso posto, partes que, a princípio, poderiam ser vazias do ponto de vista argumentativo e autoral, são preenchidas de intencionalidades durante o planejamento textual. Como exemplo, encontram-se as sequências descritivas aqui elucidadas, que, mesmo classificadas como tal, carregam 
um forte viés argumentativo, já que foram empregadas com o propósito de garantir a tese defendida. Além das sequências descritivas, destaca-se a seleção lexical, delimitada, principalmente, por palavras que exprimem "juízos de valor" e, nesse sentido, também guardam carga argumentativa, como: "potencial cognitivo", "relevante", "prudente", "deve ser" e "rico".

\section{Lócus do plano de texto, da argumentação e da autoria no ENEM}

Tendo como base uma bibliografia diversificada, a seção anterior explicitou a relação teórica existente entre o plano de texto, a argumentação e a autoria. Ancorandose nessa premissa, nesta seção, o enfoque recairá sobre como esses aspectos textuais são contemplados na Matriz de Referência da Redação do Enem (BRASIL, 2019) e, depois, em um texto extraído da Cartilha do Participante (BRASIL, 2020).

De início, é preciso pontuar que a redação do Enem é avaliada de acordo com cinco competências, sendo que cada uma delas vale duzentos pontos, totalizando, assim, a nota 1000 (BRASIL, 2020). Para este trabalho, interessa a competência III, que corresponde à habilidade de "selecionar, relacionar, organizar e interpretar informações, fatos, opiniões e argumentos em defesa de um ponto de vista" (BRASIL, 2019, p. 4). Esse critério é pertinente para o presente estudo porque "[...] na avaliação de redações, o conceito de autoria se mostra relacionado ao projeto de texto elaborado e ao desenvolvimento de informações, fatos e opiniões trazidos pelo participante para sua redação" (BRASIL, 2019, p. 13). Em outras palavras, a Matriz de Referência do Enem reforça a associação entre o plano de texto, a argumentação e a autoria.

Em linhas gerais, o material que aborda a Competência III apresenta (i) as expectativas da referida competência; (ii) as habilidades mobilizadas para concretizá-la; (iii) a sua relação com as competências II, IV e V; (iv) a grade dessa competência; (v) as nomenclaturas necessárias para entendê-la; (vi) a análise dos níveis, que pode ir de 0 a 5; (vii) a comparação dos níveis 4 e 5; e, por fim, (viii) a avaliação nas competências II e III, buscando evidenciar a diferença entre elas.

No primeiro tópico, é enfatizado que se espera, por parte do candidato, a capacidade "[...] de selecionar os argumentos mais adequados, relacioná-los, organizálos de forma clara e estratégica, além de interpretá-los, desenvolvendo-os para uma efetiva defesa do ponto de vista" (BRASIL, 2019, p. 4). Em relação às habilidades suscitadas, o foco se volta para os verbos que compõem a competência em destaque: selecionar, relacionar, organizar e interpretar. Assim, é preciso, respectivamente, escolher, encadear, hierarquizar e analisar, criticamente e de forma estratégica, as informações que serão utilizadas, de modo que o candidato possa demonstrar a 
existência de um repertório sem que, para isso, mobilize conhecimentos que pouco colaboram para a construção da argumentação.

Em seguida, observa-se que há pontos em comum entre a competência III e algumas outras, como a II, por exemplo, já que ambas avaliam a questão temática. Por outro lado, a grade se refere aos níveis ( 0 a 5$)$ de proficiência que o candidato pode apresentar na competência em foco.

Além disso, destaca-se a necessidade de interpretar corretamente os principais termos que aparecem na grade específica, como: sem direção, fazendo referência ao texto que apresenta dados desconexos; com direção, ou seja, informações organizadas que apontam para um mesmo ponto de vista; projeto de texto, que é um "planejamento prévio à escrita da redação [...]" (BRASIL, 2019, p. 11) e, ao final, desenvolvimento, que diz respeito à noção de saber sustentar os argumentos escolhidos, de forma a não deixar "[...] para o leitor a tarefa de fazer as relações entre as informações, fatos e opiniões" (BRASIL, 2019, p. 13).

Em paralelo com a grade da competência III, encontra-se a descrição dos níveis (0 a 5), que aponta o esperado em cada um desses graus e, ao mesmo tempo, exemplifica tais níveis com redações do Enem. Ainda sob um viés que pondera os níveis da competência III, constata-se que a diferença entre o 4 e o 5 é muito tênue, ao indicar "[...] a diferença entre um texto que apresenta poucas falhas (nível 4) e outro, que apresenta apenas deslizes pontuais (nível 5)" (BRASIL, 2019, p. 32), dado que essa diferença não é balizada por termos quantitativos.

Sob essa perspectiva, tais falhas são compreendidas como "[...] aquelas que prejudicam, em alguma medida, a progressão do texto, uma vez que são aspectos importantes para a discussão, que não estão trabalhados de maneira satisfatória" (BRASIL, 2019, p. 37). Nessa mesma linha de raciocínio, os deslizes pontuais são aqueles que não atrapalham a progressão textual. Por fim, quanto à independência das competências II e III, o material do Inep salienta que a primeira está mais relacionada à utilização da interdisciplinaridade, enquanto a segunda corresponde ao projeto de texto e à argumentação.

Após esse panorama da competência III do Enem, e com vistas a deixar esta proposta de estudo mais didática, será analisada uma redação nota 1000 do Enem 2019 (Figura 1), atentando-se para o projeto textual, para a argumentação e para a autoria desse exemplar, que, por sua vez, abordou o tema "A democratização do acesso ao cinema no Brasil". Essa redação de texto foi escolhida por apresentar um plano de texto de forma bastante sistemática e clara, favorecendo, assim, a sua desconstrução com vistas à ilustração dos conceitos mobilizados na primeira seção deste artigo. Contudo, outras redações da Cartilha do Participante poderiam ser objeto de análise em razão da sua qualidade textual e argumentativa. 
Figura 1 - Exemplo de Redação nota 1000

Na obra "A Invenção de Hugo Cabret", é narrada a relação entre um dos pais do cinema, Georges Mélies, e um menino órfão, Hugo Cabret. A ficção, inspirada na realidade do começo do século XX, tem como um de seus pontos centrais o lazer proporcionado pelo cinema, que encanta o garoto. No contexto brasileiro atual, o acesso a essa forma de arte não é democratizado, o que prejudica a disponibilidade de formas de lazer à população. Esse problema advém da centralização das salas exibidoras em zonas metropolitanas e do alto custo das sessões para as classes de menor renda.

Primeiramente, o direito ao lazer está assegurado na Constituição de 1988, mas o cinema, como meio de garantir isso, não tem penetração em todo território brasileiro. O crescimento urbano no século XX atraiu as salas de cinema para as grandes cidades, centralizando progressivamente a exibição de filmes. Como indicativo desse processo, há menos salas hoje do que em 1975 , de acordo com a Agência Nacional de Cinema (Ancine). Tal fato se deve à falta de incentivo governamental - seja no âmbito fiscal ou de investimento - à disseminação do cinema, o que ocasionou a redução do parque exibidor interiorano. Sendo assim, a democratização do acesso ao cinema é prejudicada em zonas periféricas ou rurais.

Ademais, o problema existe também em locais onde há salas de cinema, uma vez que o custo das sessões é inacessível às classes de renda baixa. Isso se deve ao fato de o mercado ser dominado por poucas empresas exibidoras. Conforme teorizou inicialmente o pensador inglês Adam Smith, o preço decorre da concorrência: a competitividade força a redução dos preços, enquanto os oligopólios favorecem seu aumento. Nesse sentido, a baixa concorrência dificulta o amplo acesso ao cinema no Brasil.

Portanto, a democratização do cinema depende da disseminação e do jogo de mercado. A fim de levar os filmes a zonas periféricas, as prefeituras dessas regiões devem promover a interiorização dos cinemas, por meio de investimentos no lazer e incentivos fiscais. Além disso, visando reduzir o custo das sessões, cabe ao Ministério da Fazenda ampliar a concorrência entre as empresas exibidoras, o que pode ser feito pela regulamentação e fiscalização das relações entre elas, atraindo novas empresas para o Brasil. Isso impediria a formação de oligopólios, consequentemente aumentando a concorrência. Com essas medidas, o cinema será democratizado, possibilitando a toda a população brasileira o mesmo encanto que tinha Hugo Cabret com os filmes.

Fonte: Brasil (2020, p. 39)

Em um primeiro momento, cabe pontuar que, dentre as estratégias utilizadas para apresentar uma temática, destacam-se seis: a tradicional, a fotográfica, a histórica, a conceitual, a jornalística e a cultural (RABIN, 2014). A redação na Figura 1, escrita pelo candidato Gabriel Merli, é iniciada por uma estratégia cultural, caracterizada pelo uso de um elemento artístico, que pode ser um filme, uma música ou um livro, por exemplo.

Na produção em pauta, evidencia-se que o filme utilizado para contextualizar o tema se relaciona muito bem com a tese, apresentada logo em seguida. Sendo assim, o uso produtivo desse repertório revela a existência de um plano de texto estratégico, já 
que não houve a simples inserção de uma referência interdisciplinar: houve o cuidado de associá-la ao ponto de vista do participante.

A partir desse planejamento textual, a argumentação e a autoria foram reforçadas, pois, ao relacionar a obra cinematográfica com o seu posicionamento, o autor confere mais credibilidade à sua opinião e, ao mesmo tempo, demonstra autoria, tendo em vista que essa articulação entre filme e tese não deriva de um modelo genérico, mas, sim, de uma construção original e particular. Esse modo particular de estruturar o texto, que, como será visto a seguir, aparece do início ao fim da redação, ilustra a definição de "autor" dada por Possenti (2013, p. 243, grifo do autor), segundo a qual "[...] o autor se caracteriza pelo controle de um texto não convencional (quem controla um texto comum é apenas um sujeito 'normal')".

Somada a isso, a construção do parágrafo introdutório, como um todo, ilustra o planejamento textual, já que as três partes básicas da introdução (contextualização temática, tese e argumentos) foram cumpridas com excelência, auxiliando, assim, na força argumentativa e na autoria. Isso acontece, pois respeitar a ordem dessa tríade estrutural facilita a visualização de um direcionamento argumentativo e estratégico. No entanto, quando não utilizada de forma autoral, essa organização preestabelecida pode se transformar na reprodução de modelos prontos, que se fixam em informações genéricas, ou seja, passíveis de serem utilizadas em vários temas.

Sob essa ótica, a autoria desse texto é, mais uma vez, potencializada, pois as informações mobilizadas não são abrangentes. Pelo contrário, são específicas, de modo que o repertório, a tese e os argumentos dificilmente poderiam ser reaproveitados em outros temas. Esse arranjo também atende às habilidades requeridas na competência III, dentre as quais espera-se que o candidato seja capaz "[...] de selecionar os argumentos mais adequados, relacioná-los, organizá-los de forma clara e estratégica, além de interpretá-los, desenvolvendo-os para uma efetiva defesa do ponto de vista" (BRASIL, 2019, p. 4).

O segundo e o terceiro parágrafos, por sua vez, também fomentam que a redação nota 1000 em análise possui um plano de texto, uma argumentação consistente e indícios de autoria. Essa premissa se sustenta na ideia de que houve uma organização prévia, anterior à escrita propriamente dita, a partir da qual o escrevente articulou dois tópicos frasais - período responsável por iniciar os parágrafos de desenvolvimento -, bem como selecionou informações pertinentes para a defesa de seu ponto de vista, a saber: a Constituição Federal, o crescimento urbano do século XX, um dado da ANCINE e uma máxima do pensador inglês Adam Smith.

Ainda visando a analisar os parágrafos intermediários, evidenciam-se as frases finais apresentadas, respectivamente, neles: "Sendo assim, a democratização do acesso ao cinema é prejudicada em zonas periféricas ou rurais." e "Nesse sentido, a 
baixa concorrência dificulta o amplo acesso ao cinema no Brasil.". Isso posto, tais períodos acentuam a argumentatividade do texto, funcionando como uma síntese do que foi exposto antes e confirmando que o planejamento textual contribui para a argumentação. Para além disso, os próprios elementos coesivos "sendo assim" e "nesse sentido" constituem, conforme aponta a competência IV, "[...] mecanismos linguísticos necessários para a construção da argumentação" (BRASIL, 2020, p. 8). Sob outra perspectiva, a autoria, no desenvolvimento 1, é evidenciada pelo uso produtivo de duas referências do texto motivador IV4: a magnitude do cinema brasileiro em 1975 e a urbanização.

Gabriel Merli demonstra forte autoria ao transpor tais repertórios para seu texto com muita identidade, ou, como diria Possenti (2013), tendo "controle" sobre seu texto e conferindo-Ihe o caráter não convencional. Uma das estratégias usadas pelo candidato consiste em uma paráfrase cuidadosa do texto motivador, ilustrada, sobretudo, pela substituição lexical de "urbanização" por "crescimento urbano", bem como pela inserção da palavra "hoje" na quarta linha do desenvolvimento 1, a qual constrói um paralelo entre o passado (1975) e a atualidade, sem contar que tal termo não foi explicitado no texto IV.

Por fim, a autoria, no tocante a "dar voz aos outros" (POSSENTI, 2002), também se concretiza na preocupação em citar a ANCINE, que, no contexto, funciona como uma fonte de pesquisa e aparece no link que vem após o texto motivador IV; esse caráter discreto que, às vezes, faz com que os alunos ignorem a fonte de onde a informação foi extraída, não foi negligenciada por Gabriel Merli e ainda o auxiliou a conferir mais credibilidade ao dado pelo recurso à argumentação por autoridade.

No que se refere à conclusão, constata-se que a primeira frase - a retomada da tese - confirma o projeto de texto que envolveu os parágrafos anteriores, pois a reformulação dos argumentos, explicitada, nesse período inicial, demonstra que tal construção linguística foi pensada com antecedência, ou seja, antes da redação do texto em si, em correspondência com o conceito de projeto de texto delimitado pelo Inep e já mencionado anteriormente.

Ademais, essa mesma reformulação dos argumentos acentua a argumentação, tendo em vista que a escolha por vocábulos diferentes para remeter à mesma ideia não serve, apenas, para evitar a repetição de palavras, mas também para introduzir um direcionamento argumentativo extra. Em outras palavras, do ponto de vista argumentativo, "disseminação" é diferente de "centralização das salas exibidoras em

\footnotetext{
4 Por não ser o foco deste trabalho, a proposta de redação completa, com os respectivos textos de apoio, não foi destacada. No entanto, caso seja pertinente, ela se encontra disponível em: https://download.inep.gov.br/educacao_basica/enem/provas/2018/1DIA_01_AZUL_BAIXA.pdf . Acesso em: 20 dez. 2021.
} 
zonas metropolitanas", bem como "jogo de mercado" expressa um valor argumentativo distinto de "alto custo das sessões para as classes de menor renda". Nesse prisma, a paráfrase desses argumentos no começo da conclusão sinaliza originalidade, visto que essa seleção lexical evidencia uma forma singular de expressão do sentido, configurando o estilo do autor nesse texto e colaborando para que se possa, pois, qualificá-lo como apresentando indícios de autoria (POSSENTI, 2002).

Em seguida, após a retomada da tese, encontra-se a proposta de intervenção, particularidade exclusiva do Enem, que consiste em elaborar duas soluções detalhadas para o problema exposto no tema. No que tange à proposta de intervenção de Gabriel Merli, ambas as soluções retomam os dois argumentos do texto, de modo que a primeira faz referência ao primeiro argumento, que é a concentração cinematográfica nas metrópoles, enquanto a segunda está associada ao segundo argumento: 0 alto valor das sessões de cinema. Nesse viés, essa correspondência clara entre argumento e solução permite vislumbrar, novamente, um plano textual que auxilia na argumentação e na autoria, pois conseguir sustentar o mesmo ponto de vista, da introdução à conclusão, é um aspecto crucial da argumentação. Por outro lado, quanto à autoria, o direcionamento argumentativo do texto já anunciava medidas como essas na conclusão, o que é um sinal tanto de autoria quanto de planejamento textual, visto que os parágrafos dialogam um com o outro.

Em última instância, o final da redação: "com essas medidas, o cinema será democratizado, possibilitando a toda população brasileira o mesmo encanto que tinha o Hugo Cabret com os filmes" corrobora, com maestria, o preciosismo do projeto textual de Gabriel, uma vez que há, no parágrafo final, uma retomada da referência interdisciplinar utilizada na introdução, de modo a relacionar um extremo do texto com o outro. Sob essa perspectiva, conseguir resgatar um repertório que legitima o potencial dessa referência intensifica a argumentação e demarca a autoria, no sentido da identidade da introdução ter sido recuperada no final.

Após a análise dessa redação nota 1000, retirada do manual do candidato (BRASIL, 2020), constatou-se, na prática, que o plano de texto favorece a argumentação e a autoria - sendo assim, muito importante para a redação do Enem, já que essa segue a tipologia dissertativo-argumentativa e demanda, conforme prevê a competência III, traços autorais. Além disso, também se verifica que a produção analisada reflete a definição de texto apresentada por Marquesi, Elias e Cabral (2017, p. 14), para quem "[...] o texto constitui uma construção organizada de forma estrutural cuja finalidade é cumprir os propósitos comunicativos do gênero que ele materializa". Essa construção organizada segundo uma estrutura se evidenciou pela decomposição do texto nos aspectos recortados neste artigo, os quais mostram o plano de texto pela seleção e pela 
mobilização de estratégias argumentativas variadas e pela diversidade do seu agenciamento.

Por último, para uma análise minuciosa de redações modelo Enem, cabe retomar a importância de entender, principalmente, dois termos mencionados na grade específica da Competência III: projeto de texto e desenvolvimento, os quais já foram elucidados antes, mas, a título de lembrança, serão revisitados, almejando uma correlação entre teoria e prática. Nessa ótica, os referidos vocábulos guiaram a análise do texto selecionado como corpus, de modo que essa se ancorou, sobretudo, na necessidade de um "planejamento prévio à escrita da redação [...]" (BRASIL, 2019, p. 11), bem como no potencial do desenvolvimento, observando se esse não deixava "[...] para o leitor a tarefa de fazer as relações entre as informações, fatos e opiniões" (BRASIL, 2019, p. 13).

Ao lado do projeto de texto e do desenvolvimento, o caráter autoral também permeou nossa análise, ao passo que "[...] na avaliação de redações, o conceito de autoria se mostra relacionado ao projeto de texto elaborado e ao desenvolvimento de informações, fatos e opiniões trazidos pelo participante para sua redação" (BRASIL, 2019, p. 13).

Percebe-se, pois, que, apesar de não haver menção explícita a uma subárea específica da Linguística na matriz de referência para correção das redações do Enem, é possível encontrar convergência com as definições dos conceitos de plano de texto e autoria apresentadas por autores como Adam (2005), Cabral (2013), Marquesi, Elias e Cabral (2017) entre outros.

\section{Considerações finais}

Diante do exposto, o objetivo geral deste estudo, que era discutir a relação entre plano de texto, argumentação e autoria, foi alcançado, já que a primeira seção se ocupou de explicitar a interdependência teórica existente entre eles, e a segunda seção mostrou essa relação em uma redação nota mil, inserida na Cartilha do Participante (BRASIL, 2020). Assim, a partir da análise do referido texto, verifica-se que o cuidado com o planejamento textual potencializa a argumentação e a autoria, particularidades tão importantes, sobretudo, em gêneros de natureza argumentativa.

Embora não tenha sido o foco da proposta, acredita-se que este trabalho possa ampliar os horizontes do ensino de Produção Textual e, mais especificamente, da redação do Enem, servindo de material didático-metodológico para docentes da área. Isso porque os critérios de planejamento que envolvem a confecção de bons textos podem ser transpostos para outros contextos didático-pedagógicos, à medida que 
auxiliam a construir parâmetros para outras produções, independente do gênero ao qual elas pertencem.

Nesse sentido, embora a ênfase deste trabalho recaia na articulação entre plano de texto, argumentação e autoria, vale salientar a relevância e a necessidade não apenas dos estudos acerca dos mecanismos de construção textual para atender aos critérios de avaliação definidos pelo Inep para a redação Enem, mas também aqueles que se dediquem a questões linguísticas transversais a toda e qualquer produção, tais como o uso de operadores argumentativos e seus efeitos semânticos, a estrutura da frase e do parágrafo, a modalização e os seus efeitos no discurso, entre inúmeros outros. Esse movimento de reflexão sobre o uso da língua possibilita ultrapassar os limites e as finalidades da escrita da redação, reverberando em práticas que vão além da situação de avaliação aqui descrita.

Somada a isso, a possibilidade de pesquisa futura não é esgotada, haja vista a potencialidade desse objeto de estudo, capaz de se desdobrar em muitos artigos, os quais podem manter, como corpus, o gênero redação do Enem ou podem selecionar um gênero diferente, além de enfocar outros ângulos da tríade plano de textoargumentação-autoria. Nesse sentido, conforme já mencionado, a mobilização de outras abordagens teóricas, tais como a Teoria dos Blocos Semânticos, a Teoria Semiolinguística, a Retórica e a Nova Retórica, apenas para mencionar algumas, poderia ampliar não só as possibilidades de estudo do gênero redação, especificamente, mas também favorecer o desenvolvimento de estratégias de ensinoaprendizagem da escrita, de uma maneira geral.

\section{Referências}

ADAM, Jean-Michel. La linguistique textuelle: introduction à l'analyse textuelle des discours. Paris: Armand Colin, 2005.

BARBISAN, Leci B. A produção de discursos argumentativos na escola. Revista Desenredo, v. 1, n. 2, 2005.

BRASIL. Ministério da Educação. Base Nacional Comum Curricular. Brasília, 2018.

BRASIL. Instituto Nacional de Estudos e Pesquisas Educacionais Anísio Teixeira (Inep). Redações Enem 2019: material de leitura, módulo 05, competência III. Brasília: INEP, 2019.

BRASIL. Instituto Nacional de Estudos e Pesquisas Educacionais Anísio Teixeira (Inep). A redação no Enem 2020: cartilha do participante. Brasília: INEP, 2020.

CABRAL, Ana Lúcia Tinoco. O conceito de plano de texto: contribuições para o processo de planejamento da produção escrita. Linha D’Água, v. 26, n. 2, p. 241-259, 2013.

DUCROT, Oswald. Princípios de Semântica Linguística: dizer e não dizer. São Paulo: Cultrix, 1987. 
MARCUSCHI, Luiz Antônio. Gêneros textuais: definição e funcionalidade. In: DIONISIO, Angela; MACHADO, Ana Raquel; BEZERRA, Maria Auxiliadora (orgs.). Gêneros textuais \& ensino. São Paulo: Parábola Editorial, 2010. p. 19-36.

MARQUESI, Sueli; ELIAS, Vanda; CABRAL, Ana Lúcia. Planos de texto, sequências textuais e orientação argumentativa. In: MARQUESI, Sueli; PAULIUKONIS, Aparecida; ELIAS, Vanda. Linguística textual e ensino. São Paulo: Contexto, 2017. p. 13-32.

MARQUESI, Sueli et al. Plano de texto contexto: conceitos em interface para o tratamento da escrita e da leitura em mídia digital. Revista (Con)Textos Linguísticos, Vitória, v. 13, n. 25, p. 40-59, 2019.

OLIVEIRA, Lucas; QUEIROZ, Maria E. Plano de texto e produção escrita: a construção composicional de gêneros na Base Nacional Comum Curricular (BNCC). Revista (Con)Textos Linguísticos, Vitória, v. 14, n. 29, p. 299-319, 2020.

PLATÃO, Francisco; FIORIN, José Luiz. Lições de texto: leitura e redação. São Paulo: Ática, 2005.

POSSENTI, Sírio. Indícios de autoria. Perspectiva, Florianópolis, v. 20, n. 1, p. 105-124, 2002.

POSSENTI, Sirio. Notas sobre a questão da autoria. Matraga, Rio de Janeiro, v. 20, n.32, p. 239-250, 2013.

RABIN, Bruno; PINNA, Rafael; BIAR, Liana. Pré-vestibular social: redação. v. 1. Rio de Janeiro: Fundação Cecierj, 2014.

REBOUL, Olivier. Introdução à retórica. 2. ed. Tradução: Ivone Castilho Benedetti. São Paulo: Martins Fontes, 2004.

SANTOS, Leonor Werneck dos; LEBLER, Cristiane Dall' Cortivo. Texto, gramática e ensino: o conceito de análise linguística/semiótica. In: WIEDERMER, Marcos Luiz; OLIVEIRA, Mariangela Rios (org.). Texto e gramática na Educação Básica: novos contextos, novas práticas. Campinas: Pontes, 2021. p. 45-76. 